\title{
THE IMPACT OF PRICING ON TIME-ON-MARKET IN HIGH-RISE MULTIPLE-UNIT RESIDENTIAL DEVELOPMENTS
}

\author{
WEI-FAN LI \\ National University of Singapore
}

\begin{abstract}
Previous studies on the price and time trade-off in real estate focused primarily on the real estate traded in the secondary market. This relation, however, depends rather critically on seller motivations. This study examines the price and time trade-off for new residential developments where developer motivations differ substantially from individual seller motivations. In addition, by using the information in listing and selling prices, we seek to evaluate how the two measures of overpricing affect the speed at which new developments are sold. Using high-rise multiple-unit condominium data from Singapore, our empirical analysis shows that the overpricing strategy does not pay off, but leads to longer time on the market (TOM). Furthermore, the factors about competitor behaviour have significant influence on TOM through their impact on listing price. It also shows that buyers are more price-sensitive when there are some competitors in the same area and period.
\end{abstract}

\section{INTRODUCTION}

Illiquidity is an intrinsic feature of the real estate market. The relationship between time-on-market (TOM) and price is a widely accepted manifestation of real estate illiquidity. Brealey and Myers (1988) stated "Liquidity means that you do not have to accept a discount from true value if you want to sell the asset quickly". As early as Bagehot (1971), "Liquidity is inversely related to the price spread".

Much of the literature on TOM focuses on the conflicting objectives of a property seller: maximizing the selling price and minimizing TOM. This study differs from earlier work which shows that the relationship depends rather critically on seller motivations, because they have focused primarily on real estate traded in the secondary market. This study examines the price and time trade-off for new residential developments where the seller (developer) offers multiple units for sale. By using listings and transactions of new pre-sale high-rise condominium properties, we re-examine the influences on price and TOM for institutional sellers rather than individual sellers. To the extent that developers are sellers that are likely to play a repeated game (as opposed to individual sellers who may regard their sale as a one-off game), factors such as reputation, competitor behaviour, inventory costs, etc. should matter.

Pacific Rim Property Research Journal, Vol 10, No 3 
Focusing on new developments offers us a unique opportunity to examine the effect of competitor behaviour on pricing and TOM. To the best of our knowledge, there has been very little empirical research on the competitor behaviour pertaining to the developer's price strategy. One difficulty is the definition of good proxies for the competitor strategy. In addition, the real estate market is often an oligopolistic market where pricing is often used as a competitive instrument. Therefore, price strategy which affects TOM cannot be made without regard to other developer's actions. This paper analyses several variables that reflect the competitor strategy.

As this study examines the relationship between TOM and price for high-rise condominiums, it is inevitable that we examine the floor level as a new factor affecting TOM. In general, home buyers usually prefer high-level properties because of better view/ventilation and privacy. But units on high floors also sell for higher prices.

In addition, we re-examine the issue of overpricing. Two definitions of the Degree of Overpricing (DOP) are utilized. The first definition uses the difference between listing and predicted listing price, that captures, in part, the seller strategy. In the second definition, DOP is computed as the percentage difference between the listing price and the predicted selling price. Because the selling price is the marketadjusted price after private negotiation and bargaining, the second definition of DOP encompasses a wider set of information about sales than the first.

The empirical analysis confirms the prediction that an overpricing strategy will lead to longer TOM under both DOP definitions. This result suggests that developers adopt appropriate listing price strategies. In addition, the physical and location characteristics of the property directly affect TOM, although some are not significant in explaining TOM. Most significantly, we find that factors measuring competitor behaviour have an influence on TOM through their impact on listing price, indicating that buyers are price-sensitive when competing projects are available in the same geographic area. As such, developers respond to competition by refraining from listing at higher prices even when market demand is good.

The paper is organized as follows. In the next section, the literature review is briefly provided. Section 3 presents the methodology. Section 4 describes the data and predicts the impact of specific factors on price and TOM. Section 5 shows the empirical results. The last section is a summary of the paper.

\section{BACKGROUND}

Recent studies have related overpricing (DOP) to the illiquidity of housing markets by way of search and bargaining models. Extant research have examined a wide set of factors that affect TOM, e.g. change in listing price, selling motivation, buyers' information, atypical property characteristics, market condition and brokers' 
behaviour. The information in the listing price and the predicted listing price are used to define DOP in some recent research.

A 2-stage methodology is widely used. In Knight (2002), a 2-stage least squares (2SLS) model was adopted to explore the impact of the information about the change from the listing price to the selling price on TOM. The missing information in the initial listing price is costly to sellers in terms of time and money. Yavas and Yang (1995a) used the 2SLS model and search theory to decide the ratio between the predicted selling price and listing price and TOM in a price sub-group. The result was that an increase in the ratio could decrease TOM in mid-priced properties. Ong and Koh (2000) and Forgey et al. (1996) also utilized a 2-stage model.

Bargaining and economic search theory have been well established in TOM studies. Yavas and Yang (1995a) examined the role of the listing price in attracting potential buyers. The listing price influences TOM because it acts as a signal to potential buyers, hence affects the rate at which buyers inspect a property. Haurin (1988) used an optimal stopping rule strategy to study seller behaviour. Turnbull and Sirmans (1993) showed that the housing market was efficient to protect the less informed buyers from paying more once the physical conditions, location and other property characteristics had been controlled. The discount which accounted for the bargaining power was not significantly different between first-time and repeated buyers. Arnold (1999) extended the bargain progress to more complex strategic relationships among buyers, sellers and agents. Forgey et al. (1996) also provided a theoretical framework of the economic search model.

Some research relates the trade-off between price and TOM to the liquidity. There are two ways to measure the liquidity of the housing market: price spread and TOM. Jud et al. (1995) defined the price spread (the ratio of difference between the listing price and the selling price to listing price) as a measure to the liquidity of the housing market. 2SLS was used to show that TOM increases with the price spread though it was not significant and the mortgage rate decreases with the spread. Kluger and Miller (1990) adopted the odds ratio to construct a liquidity measure to sale probability with a change of each independent variable. The study of Forgey et al (1996) was different from earlier studies. Liquidity is proxied as the percentage of the difference between the actual TOM and the expected TOM. The proxy was inversely related to the selling price.

Haurin (1988) concluded that the more atypical a property was, the longer its TOM would be. His study was one of the classic applications to the duration model of TOM in the housing market

Research on the trade-off between the selling price and TOM usually use the behaviour of the sellers to test their views; however, few articles analyse the behaviour of buyers. Anglin (1997) examined TOM from the buyers' perspectives 
by questionnaires. He concluded that the prior information and more useful information from the real estate agent could shorten TOM, and the type of agency and personal characteristics had little effect on the buyers.

Seller motivations are also important. Glower et al. (1998) found the seller motivations could influence TOM and the selling price. The coefficients on variables relating to seller motivation were significantly negative but atypicality was not significant, which was different from Haurin (1988) and Jud et al. (1996).

Listing price changes have also been focused in recent studies. Knight (2002) incorporated the listing price changing information into TOM. In addition, properties with large percentage changes in the list price took longer to sell. It was quite reasonable that the sellers of such properties would become discouraged and impatient for sales and would accept lower offers.

Market conditions were included in Anglin et al. (2003). An increase in market inventory lengthened TOM for an individual seller. Kalra and Chan (1994) also showed that regional economic conditions had a great influence on TOM.

Sirmans et al. (1991) was the first to integrate the housing market and real estate broker service market into a simultaneous equation. They provided the 2 -stage nonlinear model to find that the larger firms sold properties faster than the smaller ones, brokers did not sell self-list property faster, and sellers did not give the higher commission to faster brokers.

\section{METHODOLOGY}

As with earlier studies, we adopt the 2-stage methodology in this study. The advantage of the 2-stage measure is to solve the Simultaneity Problem (Yavas and Yang, 1995a) between TOM and property price. In the first stage, we regress the selling price or listing price on pertinent factors as property characteristics and competitor behaviour to get the predicted selling price or the predicted listing price, which we regard as the market-adjusted price.

Apart from some US research that used only the listing price to calculate the DOP (Anglin et al., 2003; Jud et al., 1996), we additionally provide the predicted selling price to get the DOP because the type of data we adopt is different. The data for these papers came from the Multiple Listing Service (MLS) and were partly resale data. In their dataset, every seller could make his listing price according to personal situations. Thus, every property listing price in the MLS accounted for a strategy of an individual seller in the transaction. Since our research focuses on new-sale units of condominiums in Singapore, the listing price of every unit in a project is decided by the developer. As a result, the developer is not likely to have a separate price strategy for every individual unit like a re-sale seller. To this end, the selling price 
will be used as the variable for another kind of DOP as well, because the selling price is the actual observed market-adjusted prices. However, information of a seller's original listing price which directly reflects the seller strategy is also important to DOP. Hence, we define two types of DOP which either include the predicted listing price or the predicted selling price.

We adopt a 2-stage approach in our estimation.

\section{The first stage: obtaining DOP}

In the first step, the predicted listing price and predicted selling price is estimated by the regression functions: equations (1a) and (1b).

$$
\begin{aligned}
& E(\log (L P))=C+a_{H}{ }^{\prime} X_{H}+a_{R}{ }^{\prime} X_{R}+a_{T}{ }^{\prime} X_{T}+a_{P}{ }^{\prime} X_{P}+a_{C}{ }^{\prime} X_{C} \\
& E(\log (S P))=C+\varepsilon_{H}{ }^{\prime} X_{H}+\varepsilon_{R}{ }^{\prime} X_{R}+\varepsilon_{T}{ }^{\prime} X_{T}+\varepsilon_{P}{ }^{\prime} X_{P}+\varepsilon_{C}{ }^{\prime} X_{C}
\end{aligned}
$$

Equations (1a) and (1b) are log-linear regression functions which describe the influence on the listing price and the selling price in terms of some possible factors. $X_{H}$ accounts for the property characteristics which are widely used in earlier studies. $X_{R}$ and $X_{T}$ respectively count for the dummy variables for region and tenure. $X_{P}$ is a price index for condominium property to control for change in market conditions. $X_{C}$ includes the variables that reflect competitor strategy.

In the selling price model, however, only uncensored data (we define a property with censored unit as the property that has not been sold before a deadline) are used in the first stage regression (equation 1b). In order to utilize the information from censored data in the second stage, we use coefficients estimated from the uncensored data for this censored data set. To be specific, we put the value of the censored data into the regression function, i.e. the first stage function in the selling price model.

Thus, the systematic components affecting the property price have been captured. The residuals of the listing price model (equation 1a) and selling price model (equation 1b) are reasonable to be used to estimate DOP. In this paper, DOP1 is defined as the ratio of residential of listing price model to the natural logarithm of the listing price (equation 2a), and DOP2 is defined as the ratio of residential of selling price model to the natural logarithm of the selling price (equation $2 \mathrm{~b}$ ). DOP will play an important role in the second stage.

$$
D O P 1=\frac{\log (L P)-E(\log (L P))}{\log (L P)}
$$




$$
D O P 2=\frac{\log (L P)-E(\log (S P))}{\log (L P)}
$$

\section{The second stage: TOM and DOP}

Existing empirical studies of TOM apply two types of models: duration models and linear or log-linear OLS regression models ${ }^{1}$. The popular employment of regression models for TOM is due to its simplicity (Belkin et al., 1976; Kang and Gardner, 1989; Miller, 1978; Sirmans et al., 1991; Yavas and Yang, 1995a).

Instead, this study utilizes a duration model with a Weibull distribution that is applied to test how the factors, which include degree of overpricing, property and location characteristics, region dummy, selling time dummy, tenure dummy, macroeconomic factors and competitor strategy can affect TOM.

Because the duration model has the advantage that it allows one to analyse multiple factors which affect the time until the occurrence of an event, we can apply it in the housing market. For instance, it can be particularly well suited to analyse TOM because unsold properties may be included in the research sample where the event is the sale of housing.

In our duration model, it is assumed that TOM is affected by multiple factors and has a known distribution, thus the parametric model is adopted. If the hazard rate does not vary over time (the probability of a sale is the same regardless of when the observation is made), the exponential distribution provides simple and accurate parameter estimates. However, prior studies of TOM indicated that the hazard rate was not constant (Zuehlke, 1987; Yavas and Yang, 1995a). A commonly used alternative distribution is Weibull. The Weibull distribution is a generalization of the exponential distribution with two parameters: $\mathrm{P}$ and $\beta$.

We also have also used the log-linear model and other parameter duration models, for example, exponential and log-normal, in the second stage. Although most of the coefficients of such different models are consistent in terms of magnitudes and directions, we still can justify that the Weibull model is the preferred model since it offers higher log-likelihood values than the log-linear model and other duration models. Yang and Yavas (1995b) also show that the Weibull distribution offers the best log likelihood ratio estimate.

This study utilizes a Weibull distribution duration model where:

$$
h(t)=\lambda P(\lambda t)^{P-1}
$$

\footnotetext{
${ }^{1}$ The probability density function $(\mathrm{f}(\mathrm{t}))$, the survival function $(\mathrm{S}(\mathrm{t}))$ and the hazard function $(\mathrm{h}(\mathrm{t}))$ are presented in Table 1 with respect to the Exponential, the Weibull and the Log-normal distribution.
} 
$\lambda=\operatorname{Exp}\left(-\sum \beta_{i}{ }^{\prime} \mathrm{X}_{i}\right)$

$=\operatorname{Exp}\left[-\left(\beta_{\mathrm{D}}{ }^{\prime} \mathrm{X}_{\mathrm{D}}+\beta_{\mathrm{H}}{ }^{\prime} \mathrm{X}_{\mathrm{H}}+\beta_{\mathrm{R}}{ }^{\prime} \mathrm{X}_{\mathrm{R}}+\beta_{\mathrm{T}}{ }^{\prime} \mathrm{X}_{\mathrm{T}}+\beta_{\mathrm{YS}}{ }^{\prime} \mathrm{X}_{\mathrm{YS}}+\beta_{\mathrm{M}}{ }^{\prime} \mathrm{X}_{\mathrm{M}}+\beta_{\mathrm{C}}{ }^{\prime} \mathrm{X}_{\mathrm{C}}\right)\right.$

$\mathrm{P}$ is a parameter that determines the distribution function. $\mathrm{X}$ is a vector of exogenous explanatory variables, like DOP $\left(X_{D}\right)$, property characteristics $\left(X_{H}\right)$, region dummy $\left(X_{R}\right)$, tenure dummy $\left(X_{T}\right)$, year of sale dummy $\left(X_{Y S}\right)$, macroeconomic factors $\left(X_{M}\right)$ and the competitor behaviour $\left(X_{C}\right)$. The null hypothesis of our study is that these variables do not affect TOM. $\beta^{\prime}$ is the vector of the parameters of $\mathrm{X}$. In the section of empirical results, the estimation of $\mathrm{P}$ and $\beta^{\prime}$ will be explained according to the empirical tests.

Table 1: The summary of distributions

\begin{tabular}{llll}
\hline Distribution & Density function & Hazard function & $\begin{array}{l}\text { Survival } \\
\text { function }\end{array}$ \\
\hline Exponential & $\lambda \cdot \operatorname{Exp}(-\lambda t)$ & $\lambda$ & $\operatorname{Exp}(-\lambda t)$ \\
Weibull & $\lambda P \cdot(\lambda t)^{P-1} \cdot \operatorname{Exp}\left(-(\lambda t)^{P}\right)$ & $\lambda P \cdot(\lambda t)^{P-1}$ & $\operatorname{Exp}\left(-(\lambda t)^{P}\right)$ \\
Log-normal & $\frac{P}{t} \cdot \varphi[P \ln (\lambda t)]$ & $\frac{P \cdot \varphi[P \ln (\lambda t)]}{t \cdot \phi[-P \ln (\lambda t)]}$ & $\phi[-P \ln (\lambda t)]$ \\
\hline
\end{tabular}

In Log-normal, $\ln (\mathrm{t})$ is normally distributed with mean $-\ln (\lambda)$ and standard error $1 / \mathrm{P}$

\section{DATA DESCRIPTION AND VARIABLES PREDICTION}

\section{Data description}

The data used in our study are collected from Realis data source of URA (Urban Redevelopment Authority) of Singapore and project developers. Our sample focuses on the new-sale units of high-rise condominiums in Singapore. The data set contains 2,492 property transactions in 24 condominium projects which were sold from April 2001 through September 2002 ${ }^{2}$. The 2,492 observations include 1,804 uncensored data and 688 censored data. We define a property with censored data as the property that has not been sold before December 31, 2002.

\footnotetext{
${ }^{2} 2492$ are not the number of total units of the 24 projects but just the units which are released in a same phase. The other data which are excluded in our sample but exist in the 24 projects can fall into two categories: units launched in other phases that have been sold or units that are withheld by developers for later releases. So the data in our paper are still effective since the pricing strategy for same phase may be same.
} 
Condominium properties are selected because they comprise the largest segment of Singapore's residential housing market. By using the data of new sale properties, we were able to disregard the effects of age of units, the quality of fittings, renovation and the sellers' preferences on TOM.

The definitions of dependent and independent variables in our analysis are summarized in Table 2. Table 2 also provides descriptive statistics for all the variables included in our 2-stage model ${ }^{3}$.

\section{Variables prediction}

TOM, selling price, listing price, DOP and DUR

We define TOM as the duration from the day before the first contract date, defined as the date on which the first unit in any particular project or phase is sold, to the specific contract date. The reason for doing this is that new pre-sale properties typically are not listed in a MLS and do not have an exact listing date ${ }^{4}$.

The mean TOM shows that properties are sold a little more than 2 months on average. But the maximum TOM of 502 days and the standard deviation of 82 show that there is a huge TOM distribution range because the factors affecting TOM are different.

Given that the majority of the sales are uncompleted units, DUR, which is calculated as the duration from the contract date to TOP date, is used as a proxy for the opportunity cost of holding the presale unit. It is more likely that if the opportunity cost which includes rental cost and interest is high, the buyers would prefer other projects with the earlier TOP. If DUR is longer, a lower price is expected, and also a longer TOM is expected.

\section{Property and location characteristics}

In the $1^{\text {st }}$ stage, the linear regression is estimated for LOGLP/LOGSP. However, it is possible that the relationship between them is not linear, especially to some continuous variables. We find that the LOGLP/LOGSP is better explained by adding SIZE2 in the first stage than using SIZE only. We also get better results after the FLOOR2 and PRO2 are added in the TOM model.

We predict that PM and AM, the variables reflecting the facing to west and east, will have a positive relationship with TOM. This is because living rooms that face the south or the north can avoid direct sunlight. Therefore, the units for which the living rooms face west and east are likely to have longer TOM.

\footnotetext{
${ }^{3}$ We originally add the project dummies as explanatory variables in the first-stage model. But the result is not reasonable: not only did a multicollinearity problem happen, but most of the project dummies were insignificant.

${ }^{4}$ Of the total 2492 units, there are 2480 units which have been sold before TOP.
} 


\begin{tabular}{|c|c|c|c|c|c|c|}
\hline Variable & $\begin{array}{l}\text { Dummy/ } \\
\text { Continuous }\end{array}$ & Definition & Mean & Std. Dev. & Maximum & Minimum \\
\hline \multicolumn{7}{|c|}{ TOM, Selling price, Listing price, DOP and DUR } \\
\hline TOM & $\mathrm{C}$ & Time on Market (days) & 66.93958 & 82.20375 & 502.00000 & 1.00000 \\
\hline CENSOR & $\mathrm{D}$ & 1 if the property is not sold before Dec.31 2002 & 0.72392 & 0.44715 & 1.00000 & 0.00000 \\
\hline LOGSP & $\mathrm{C}$ & Natural $\log$ of SP & 1 & 1 & 1 & I \\
\hline SP & $\mathrm{C}$ & Actual selling price (1000S\$dollar) & 629.46490 & 191.92300 & 1686.34600 & 362.00000 \\
\hline LOGLP & $\mathrm{C}$ & Natural $\log$ of LP & 1 & 1 & 1 & 1 \\
\hline LP & $\mathrm{C}$ & Listing price (1000S\$dollar) & 747.21510 & 247.23910 & 2130.00000 & 412.00000 \\
\hline DOP1 & $\mathrm{C}$ & $\begin{array}{l}\text { Degree of Overpricing (percentage difference between LOGLP and } \\
\text { predicted LOGLP) }\end{array}$ & -0.00016 & 0.01239 & 0.07992 & -0.04842 \\
\hline DOP2 & $\mathrm{C}$ & $\begin{array}{l}\text { Degree of Overpricing (percentage difference between LOGLP and } \\
\text { predicted LOGSP) }\end{array}$ & 0.02421 & 0.01340 & 0.10307 & -0.01469 \\
\hline DUR & $\mathrm{C}$ & Duration from the contract date to TOP date (days) & 1204.32100 & 394.61990 & 2333.00000 & 0.00000 \\
\hline \multicolumn{7}{|c|}{ Property and Location Characteristics } \\
\hline FLOOR & $\mathrm{C}$ & Floor level & 6.95506 & 4.86993 & 28.00000 & 1.00000 \\
\hline FLOOR2* & $\mathrm{C}$ & The square of FLOOR & 72.07945 & 101.93990 & 784.00000 & 1.00000 \\
\hline PM & $\mathrm{D}$ & $\begin{array}{l}1 \text { if the individual unit's main living room and bedroom faces the } \\
\text { evening sun }\end{array}$ & 0.31501 & 0.46461 & 1.00000 & 0.00000 \\
\hline AM & $\mathrm{D}$ & $\begin{array}{l}1 \text { if the individual unit's main living and bedroom faces the morning } \\
\text { sun }\end{array}$ & 0.32544 & 0.46863 & 1.00000 & 0.00000 \\
\hline SIZE & $\mathrm{C}$ & The floor area of individual unit ( 1000 Square feet) & 1.29274 & 0.30519 & 3.44400 & 0.46300 \\
\hline SIZE2* & $\mathrm{C}$ & The square of SIZE & 1.76428 & 1.04128 & 11.86114 & 0.21437 \\
\hline BEDROOMS & $\mathrm{C}$ & bedroom number of individual unit & 2.88884 & 0.58147 & 4.00000 & 1.00000 \\
\hline TOILETS & $\mathrm{C}$ & toilet number of individual unit & 2.87921 & 0.58506 & 6.00000 & 1.00000 \\
\hline POOL & $\mathrm{D}$ & 1 if the individual unit has direct pool view & 0.55698 & 0.49684 & 1.00000 & 0.00000 \\
\hline ROAD & $\mathrm{D}$ & 1 if the individual unit is located near to major roads and expressways & 0.00321 & 0.05658 & 1.00000 & 0.00000 \\
\hline PES & $\mathrm{D}$ & $\begin{array}{l}\text { Private Enclosed Space, like exterior space for garden: } 1 \text { if the } \\
\text { individual unit comes with PES }\end{array}$ & 0.14767 & 0.35485 & 1.00000 & 0.00000 \\
\hline \multicolumn{7}{|c|}{ Dummy Variables Relating to the Region, Tenure and Year of Sale } \\
\hline R1 & $\mathrm{D}$ & $\begin{array}{l}\mathrm{R} 1=1 ; \mathrm{R} 2=0 ; \mathrm{R} 3=0 ; \mathrm{R} 4=0 ; \text { the property is in the centre of Singapore } \\
\mathrm{R} 1=0 ; \mathrm{R} 2=1 ; \mathrm{R} 3=0 ; \mathrm{R} 4=0 \text { : in the east of Singapore }\end{array}$ & 0.19623 & 0.39722 & 1.00000 & 0.00000 \\
\hline
\end{tabular}


$\mathrm{R} 1=0 ; \mathrm{R} 2=0 ; \mathrm{R} 3=1 ; \mathrm{R} 4=0:$ in the north-east of Singapore
$\mathrm{R} 1=0 \cdot \mathrm{R} 2=0 \cdot \mathrm{R} 3=0 ; \mathrm{R} 4=1:$ in the north of Singapore

$\mathrm{R} 1=0 ; \mathrm{R} 2=0 ; \mathrm{R} 3=0 ; \mathrm{R} 4=1:$ in the north of Singapore

$\mathrm{R} 1=0 ; \mathrm{R} 2=0 ; \mathrm{R} 3=0 ; \mathrm{R} 4=0$ : in the west of Singapore

R3

R4

T99

Y2001

D

Macroeconomic Factors

MORTGAGE C

PPI

Competitor Strategy

LIST

$\mathrm{D}$

MTU

COMPSE

CTU

PRO

PRO2*

CAPITAL

CDL

MCL
KEPPEL
T99=1:the tenure is 99 years

$99=0$ :the tenure is 999 years or freehold

1 if the first sale day is in 2001

0 if in 2002

The mortgage rate of the month prior to the sale month (percentage)

Property Price Index of Condominium market in the sale quarter

Unemployment rate of the quarter prior to the sale quarter

1 if the developer is listed in leading property companies by Standard $\&$ Poor's

0 if unlisted

0 if unlisted

Take-up rate in the

1 if other competing projects are launched in the same postal sector

over the period that is 2 quarters before or after the launch date

0 if no competing projects are launched

Competitor take-up rate in the period that is 3 months before the launch quarter

The actual units of the development for sale in a phase

The square of PRO

1 if the project is developed by Capitaland Ltd

1 if the project is developed by City Development Ltd

1 if the project is developed by MCL Land Ltd

1 if the project is developed by Keppel Land Ltd

\begin{tabular}{cccc}
0.28451 & 0.45127 & 1.00000 & 0.00000 \\
0.22833 & 0.41984 & 1.00000 & 0.00000 \\
& & & \\
0.14045 & 0.34752 & 1.00000 & 0.00000 \\
& & & \\
0.79334 & 0.40499 & 1.00000 & 0.00000 \\
& & & \\
0.56180 & 0.49627 & 1.00000 & 0.00000 \\
& & & \\
6.29663 & 0.13578 & 6.45000 & 6.09000 \\
118.85440 & 3.56243 & 128.00000 & 116.00000 \\
4.31629 & 0.26227 & 4.60000 & 2.80000 \\
& & & \\
0.58588 & 0.49267 & 1.00000 & 0.00000 \\
& & & \\
0.79615 & 0.11590 & 1.13696 & 0.63011 \\
& & & \\
0.23596 & 0.42468 & 1.00000 & 0.00000 \\
& & & \\
0.07927 & 0.05054 & 0.15556 & 0.00318 \\
& & & \\
173.30900 & 80.59660 & 284.00000 & 10.00000 \\
6529.21000 & 26859.4700 & 80656.0000 & 100.00000 \\
0.15088 & 0.35801 & 1.00000 & 0.00000 \\
0.30016 & 0.45842 & 1.00000 & 0.00000 \\
0.09270 & 0.29007 & 1.00000 & 0.00000 \\
0.05498 & 0.22798 & 1.00000 & 0.00000 \\
\hline & & &
\end{tabular}

*Variables FLOOR, SIZE and PRO are entered both linearly and as squares because it is possible that the relationship between them is not linear, especially to some continuous variables. Completed description of all variables can be found in the following text. The data set is composed of 24 projects and 2492 units. 
FLOOR, POOL and PES are all predicted to have negative relationships with TOM. It is reasonable that buyers prefer properties with these better characteristics. The relationships with TOM of other three property-related variables, SIZE, BEDROOMS and TOILETS, are difficult to predict. Buyers will choose the number of bedrooms and toilets more based on their family's situation; for example, the number of family members.

The ROAD variable is expected to have a negative relationship with TOM because such properties having convenient transportation are likely to be sold after only a short time on the market. PRO is the number of units which are launched for a phase for each development. It is expected that the project with fewer units will sell faster.

Dummy variables relating to the region, tenure and year of sale

Dummy variables have also been created for region, tenure and year of sale. The base categories for them are west region, 999 year's tenure/freehold and selling time of 2002. A longer tenure will lead to shorter TOM.

\section{Macroeconomic factors}

Mortgage rate is a major contributing factor that affects TOM. Some earlier studies (Forgey et al., 1996; Jud et al., 1995; Springer, 1996) regard mortgage rate as a proxy for seller search cost comprising uncollected rent, additional mortgage payment, maintenance expenses, selling expenses and so on. The information that is easy to capture is the mortgage payment in all kinds of search costs. Thus, mortgage rate is predicted to have a negative relationship with TOM if it is an indicator of seller search cost. However, new-sale units are used in this paper, and sellers are developers. Even if a developer has a loan from a bank or a financial company to develop the project, the cost of search is the lending payment that the developer has to pay back ${ }^{5}$.

The mortgage rate can also be regarded as an indicator of the cost of homeownership when a buyer purchases a property. A lower mortgage rate reduces the cost of homeownership, everything else being equal, boosts property demand and conceivably reduces TOM. As a result, the mortgage rate is expected to be positively related to TOM in our study. Kalra and Chan (1994), Zuehlke (1987) and Yavas and Yang (1995a) also showed the positive relationship between the mortgage rate and TOM. We define the house loan for 15 years rates monthly as the mortgage rate.

\footnotetext{
${ }^{5}$ We have originally taken Prime Lending Rate as a proxy for the search cost in new-sale development because we assumed that all developers have to get a loan from financial institutions (The Prime Lending Rate in Singapore is the lowest rate at which a bank is willing to lend Singapore dollars (SGD) to its best customers on an overdraft or demand basis). But the result was not significant although it shows the negative relationship between Prime Lending Rate and TOM.
} 
Total employment is expected to be negatively related to TOM. A high employment level indicates a strong economy and leads to a shorter TOM. The local unemployment rate is used to proxy the local economy and is expected to have statistically significant positive explanatory power of TOM. However, the logic suggests that it is not the unemployment rate or number of unemployment that affects TOM. Rather, it is the level of employment that would affect TOM.

To control the changes of the housing market condition, the variable PPI (Property Price Index) of Singaporean condominium over the sample period $(2001-2002)$ is expected to have a positive relationship with property price.

\section{Competitor strategy}

The real estate market is typically an oligopolistic market where pricing is often used as a competitive instrument. The situation also exists in Singapore: there are only a few major developers selling to many buyers; for example, CapitaLand Ltd and CDL Ltd. Economic theory suggests that oligopolistic sellers are sensitive to the actions of other competitors. Therefore, a price strategy which affects TOM cannot be made without regard to other developer's actions. However, little empirical research has been carried out to evaluate the question of how developers incorporate competitor behaviour in their pricing strategy. In this paper, some variables which reflect the competitor strategy are analysed.

Usually, the take-up rate not only indicates the situation of the projects for sale, but the results of the price strategy adopted by developers as well. In Singapore, as in other countries, off-plan sales where properties are marketed prior to completion are popular in the real estate market. So the take-up rate in this paper is defined as the number of total uncompleted units sold over the total new units launched over the sample period. Competitor take-up rate (CTU) is calculated by taking the ratio of total units sold to the units launched for sale in other condominium developments in the three-month period prior to the launch month ${ }^{6}$. CTU is lagged because the developer is not likely to observe the take-up rate in the launch month.

\footnotetext{
${ }^{6}$ There is an example for how to calculate the take-up rate of competitors. We assume that project A is launched in April and only two projects B and C which are launched in January, February and March, the three continuous months. If we want to consider the influence of project $B$ and project $C$ on project $\mathrm{A}$, the take-up rate of project $\mathrm{B}$ and project $\mathrm{C}$, i.e. the take-up rate of competitors, is calculated by taking the total units sold in $\mathrm{B}$ and $\mathrm{C}$ in the three months over total units of $\mathrm{B}$ and $\mathrm{C}$ launched for sale. Another point should be also noted: the units of project $B$ and $C$ sold after the March will not be considered into the take-up rate. In addition, there are two assumptions that should be considered: Assumption1: The time influence is in the range of three months. The developer only thinks of the other projects which are launched in the three-month period before the launch month. For example, if project $\mathrm{A}$ is launched for sale in April, so the developer of project A will consider the other projects which are launched in January, February and March. Assumption2: We only consider the sale condition of the projects launched in the three months. Those projects which are launched before the three months but still have units sold in the three months are assumed to have no influence on the developer's decision.
} 
However, the effect of CTU on price and TOM can be ambiguous. A higher CTU can lead to lower listing prices because the developer takes on an aggressive price strategy, or increases the listing prices as a result of the good market demand. The uncertain relationship with listing price applies to TOM as well.

The take-up rate of the whole residential market (MTU) is the percent difference between the number of total uncompleted units sold over total new units launched in the quarter before the sale quarter. A higher MTU is predicted to increase listing price because of the stronger demand. However, it is difficult to predict the influence of MTU on TOM because the listing price also affects TOM.

The reputation of a firm is also important to explain the property price (Chau et al., 2001). The potential buyers are likely to prefer developers that have better credit and reputation. In this empirical analysis, the dummy variable LIST is the proxy for the good will of the developer: 1 if the developer is listed as a leading property company by Standard \& Poors, 0 if not ${ }^{7}$. The listing price is expected to be higher if the project is developed by the reputable developers, but the relationship with TOM is also not certain due to the listing price influence on TOM.

With the analysis for CTU, the influence of competing projects in the same neighbourhood (COMPSE) on the listing price can be two-fold: the developer will lower the listing price to compete with others; however, the situation that more projects focus on this district will show the greater demand in the area, which also stimulates the developer to improve the listing price.

The developer dummies include Capitaland, CDL, Keppel and MCL, which have more than one project in the sample. They are expected to have a higher listing price because of their prosperity and reputation in the period.

\section{EMPIRICAL RESULTS}

\section{Listing and selling price}

Most of explanatory variables are significant at the 5 percent level or better (refer to Table 3), consistent with earlier studies (Knight, 2002; Anglin et al., 2003). The Rsquare, the indicator of explanatory power of this model, is close to 91 percent in the listing price model and 90 percent in the selling price model. It shows that the Log-listing price and Log-selling price can be reasonably explained by such independent variables. The listing price model is found to have the same results as selling price model except for AM, which is negative in the listing price model but positive in the selling price model. However, AM is insignificant in both models.

\footnotetext{
${ }^{7} 12$ major leading property companies were analysed by Standard \& Poors. They include Allgreen Properties Ltd., Capitaland Ltd., CDL Ltd., Centrepoint Properties Ltd., First Capital Corp. Ltd., HDB, JTC Corp., Keppel Land Ltd., Macro Polo Development Ltd., Singapore Land Ltd., UOL Ltd. and Wing Tai Holding Ltd.
}

Pacific Rim Property Research Journal, Vol 10, No 3 
Hence, we conclude that such explanatory variables have the same influence on the listing price and the selling price. In the following analysis about price regression model, only the listing price model is analysed.

Table 3: Log-linear regression model parameters estimates in $1^{\text {st }}$ stage

\begin{tabular}{|c|c|c|c|c|c|c|}
\hline Dependent Variable & & Listing Price & & & elling Price & \\
\hline Independent Variable & Coefficient & T-statistic & Prob. & Coefficient & T-statistic & Prob. \\
\hline CONSTANT & 3.119 & 23.567 & 0.000 & 2.715 & 18.811 & 0.000 \\
\hline FLOOR & 0.007 & 16.299 & 0.000 & 0.008 & 16.350 & 0.000 \\
\hline $\mathbf{P M}$ & -0.034 & -7.458 & 0.000 & -0.014 & -2.660 & 0.008 \\
\hline AM & -0.007 & -1.637 & 0.102 & 0.002 & 0.427 & 0.669 \\
\hline SIZE & 0.960 & 25.817 & 0.000 & 0.937 & 23.316 & 0.000 \\
\hline SIZE2 & -0.165 & -17.845 & 0.000 & -0.155 & -15.396 & 0.000 \\
\hline BEDROOMS & 0.040 & 6.796 & 0.000 & 0.045 & 7.104 & 0.000 \\
\hline TOILETS & 0.036 & 6.816 & 0.000 & 0.022 & 3.766 & 0.000 \\
\hline POOL & 0.023 & 5.922 & 0.000 & 0.023 & 5.472 & 0.000 \\
\hline ROAD & 0.270 & 8.673 & 0.000 & 0.192 & 5.587 & 0.000 \\
\hline PES & -0.016 & -2.245 & 0.025 & -0.029 & -3.614 & 0.000 \\
\hline R1 & 0.047 & 4.625 & 0.000 & 0.074 & 6.454 & 0.000 \\
\hline $\mathbf{R 2}$ & 0.079 & 8.688 & 0.000 & 0.132 & 12.075 & 0.000 \\
\hline R3 & 0.091 & 9.694 & 0.000 & 0.157 & 15.608 & 0.000 \\
\hline R4 & -0.199 & -14.069 & 0.000 & -0.183 & -11.010 & 0.000 \\
\hline T99 & -0.559 & -60.177 & 0.000 & -0.513 & -51.451 & 0.000 \\
\hline PPI & 0.020 & 20.314 & 0.000 & 0.021 & 19.634 & 0.000 \\
\hline CTU & 0.978 & 11.204 & 0.000 & 1.582 & 16.645 & 0.000 \\
\hline LIST & 0.113 & 7.333 & 0.000 & 0.104 & 5.396 & 0.000 \\
\hline DUR & 0.00002 & 1.711 & 0.087 & 0.00007 & 5.625 & 0.000 \\
\hline MTU & 0.096 & 5.936 & 0.000 & 0.053 & 2.866 & 0.004 \\
\hline COMPSE & 0.238 & 23.389 & 0.000 & 0.219 & 18.407 & 0.000 \\
\hline CAPITAL & 0.037 & 1.690 & 0.091 & 0.127 & 4.451 & 0.000 \\
\hline CDL & 0.100 & 5.314 & 0.000 & 0.070 & 2.906 & 0.004 \\
\hline KEPPEL & 0.171 & 8.230 & 0.000 & 0.181 & 6.884 & 0.000 \\
\hline MCL & 0.096 & 9.950 & 0.000 & 0.107 & 10.473 & 0.000 \\
\hline R-squared & & 0.906729 & & & 0.899712 & \\
\hline Adjusted R-squared & & 0.905784 & & & 0.898302 & \\
\hline
\end{tabular}

The table that shows the results of first stage is divided into two parts. The first part is the log-linear regression which dependent variable is LOGLP. The second part is the log-linear regression which dependent variable is LOGSP. The observations in the first part include 2492 data but the second part only has 1804 uncensored data. 
Table 4: Weibull model parameters estimates in 2nd stage

\begin{tabular}{|c|c|c|c|c|}
\hline \multirow{2}{*}{ Variable } & \multicolumn{2}{|c|}{ Listing Price Model } & \multicolumn{2}{|c|}{ Selling Price Model } \\
\hline & Coefficient & t-value & Coefficient & t-value \\
\hline CONSTANT & $73.390 * * *$ & 33.071 & $73.488 * * *$ & 33.274 \\
\hline DOP1 & $2.864 * *$ & 1.983 & / & l \\
\hline DOP2 & l & / & $3.122 * *$ & 2.118 \\
\hline FLOOR & $-0.028 * *$ & -2.038 & $-0.028 * *$ & -2.073 \\
\hline FLOOR2 & $0.002 * *$ & 2.321 & $0.002 * *$ & 2.316 \\
\hline $\mathbf{P M}$ & $0.168 * * *$ & 3.609 & $0.160 * * *$ & 3.444 \\
\hline $\mathbf{A M}$ & $0.178 * * *$ & 3.926 & $0.174 * * *$ & 3.850 \\
\hline SIZE & $-0.832 * *$ & -2.365 & $-0.834 * *$ & -2.370 \\
\hline SIZE2 & $0.233 * *$ & 2.484 & $0.230 * *$ & 2.450 \\
\hline BEDROOMS & 0.035 & 0.651 & 0.032 & 0.608 \\
\hline TOILETS & $-0.084 * *$ & -1.957 & $-0.078 *$ & -1.823 \\
\hline POOL & 0.032 & 0.851 & 0.032 & 0.854 \\
\hline ROAD & $-1.352 * * *$ & -4.316 & $-1.327 * * *$ & -4.266 \\
\hline PES & -0.064 & -0.995 & -0.057 & -0.877 \\
\hline R1 & $1.009 * * *$ & 7.343 & $0.986 * * *$ & 7.045 \\
\hline $\mathbf{R 2}$ & $0.170^{*}$ & 1.743 & 0.139 & 1.427 \\
\hline $\mathbf{R 3}$ & $2.005 * * *$ & 16.022 & $1.972 * * *$ & 16.474 \\
\hline R4 & $1.950 * * *$ & 15.193 & $1.948 * * *$ & 15.193 \\
\hline T99 & -0.051 & -0.554 & -0.069 & -0.750 \\
\hline Y2001 & $1.445 * * *$ & 12.435 & $1.449 * * *$ & 12.477 \\
\hline MORTGAGE & $-11.494 * * *$ & -32.172 & $-11.484 * * *$ & -32.186 \\
\hline UNEMPLOY & $0.566^{* * *}$ & 7.681 & $0.568 * * *$ & 7.699 \\
\hline COMPSE & -0.038 & -0.427 & -0.030 & -0.333 \\
\hline CTU & $8.758 * * *$ & 6.623 & $8.557 * * *$ & 6.657 \\
\hline LIST & $-1.680 * * *$ & -12.692 & $-1.682 * * *$ & -12.726 \\
\hline DUR & $-0.002 * * *$ & -20.798 & $-0.002 * * *$ & -21.073 \\
\hline MTU & $1.500 * * *$ & 7.958 & $1.517 * * *$ & 8.067 \\
\hline PRO & $0.026 * * *$ & 12.730 & $0.026 * * *$ & 12.616 \\
\hline PRO2 & $0.00005^{* * *}$ & -14.866 & $0.00009^{* * *}$ & -14.825 \\
\hline CAPITAL & $1.371 * * *$ & 5.190 & $1.347 * * *$ & 5.137 \\
\hline CDL & $2.474 * * *$ & 12.005 & $2.473 * * *$ & 12.044 \\
\hline KEPPEL & $1.287 * * *$ & 7.353 & $1.298 * * *$ & 7.498 \\
\hline MCL & $-0.445 * * *$ & -4.421 & $-0.453 * * *$ & -4.498 \\
\hline $\operatorname{Lambda}(\lambda)$ & 0.00744 & & 0.00744 & \\
\hline $\boldsymbol{P}$ & 1.76325 & & 1.76397 & \\
\hline $\log -L$ & -1966 & & -1966 & \\
\hline $\begin{array}{l}\text { *indicates signi } \\
\text { ** indicates sig } \\
\text { ***indicates sig }\end{array}$ & $\begin{array}{l}\text { the } 10 \% \text { level } \\
\text { at the } 5 \% \text { perc } \\
\text { at the } 1 \% \text { perc }\end{array}$ & $\begin{array}{l}\text { evel } \\
\text { evel }\end{array}$ & & \\
\hline
\end{tabular}

Pacific Rim Property Research Journal, Vol 10, No 3 
Most of the variables relating to physical and location characteristics have the expected results. The significantly positive coefficient of FLOOR suggests that properties on high floors are sold at higher prices. The property price is increasing with a larger floor area (SIZE, BEDROOMS, TOILETS), a better view (POOL) and more convenient traffic (ROAD). It is worth noting that the significantly negative SIZE2 (squared size or floor area) suggests that the effect of floor area on the property price diminishes slightly with increases in the floor area: for every 1000 square feet increase in floor area, the listing price increases slightly 17 percentage points and selling price 16 percentage points. The negative coefficient of PM is also in line with the prediction. A property with east facing that is exposed to direct sunlight has a lower property price.

The tenure dummy variable T99 shows that the property with a longer tenure has a higher price. The market-controlled variable PPI has a positive relationship with the property price, which shows that the property price changes with the property market condition. DUR, the proxy for the opportunity cost of holding the pre-sale unit in the construction period, is the only result which is different from the prediction: it shows the positive relationship with listing price. The reason may be that all units in a project/phase have the same TOP date. Therefore, the developer of the project will not consider the TOP date when he lists the listing price of a unit in the project.

Of the variables about the competitor behaviour, CTU and COMPSE are predicted to have uncertain relationships with listing price, because they are not only related to competitor behaviour, but reflect the demand on the market as well. Table 3 shows that either CTU or COMPSE has a positive relationship with listing price. It shows that they rather reflect the great demand on the market than the competitor behaviour. Positive LIST indicates that the developers with good will list at higher prices. MTU, the take-up rate of whole residential market, shows a positive coefficient. It shows developers will increase the listing price when demand is perceived to be strong. The positive four developer dummies show that the listing prices of the properties of the four developers are higher than others, due to their good reputation.

\section{TOM}

Table 4 shows the results of the Weibull model respectively for the listing price model and the selling price model in the second stage ${ }^{8}$. When we compare the results in the listing price model and the selling price model, it is found that the two definitions of DOP have almost the same explanatory power to explain the

\footnotetext{
${ }^{8}$ We have also used the log-linear model and other parameter duration models, for example, exponential and log-normal, in the second stage. Although most of the coefficients of such different models are consistent in terms of magnitudes and directions, we can still justify that Weibull model is the preferred model. Weibull model offers higher log-likelihood value than Log-linear model and other duration models. Yang and Yavas (1995b) also show that the Weibull distribution offers the best log likelihood ratio estimate.
} 
relationship between TOM and the independent variables: the significance and signs of all coefficients are similar. It probably reflects the appropriateness of the price strategy adopted by developers in our sample over the period: the developer strategy (DOP1), almost has the same explanatory power to TOM as the marketadjusted overpricing strategy (DOP2). Due to the similarity of results of two definitions of DOP, we will only show and analyse the results of the listing price model later.

A problem should be noted in the analysis of second stage: some factors not only affect TOM but also the property price; particularly the property physical characteristics and competitor behaviour. Take FLOOR as an example: a property on a high floor will attract more buyers and this shortens TOM, but it has a high listing price which also leads to long TOM.

The effects of specific variables on TOM are analysed based on the Weibull distribution.

\section{DOP}

Table 4 reveals that there is a significantly positive relationship between DOP and TOM. It shows that overpricing strategy does not pay off, but leads to longer TOM.

\section{MORTGAGE}

The effect of the mortgage rate on TOM is significantly negative to TOM, contrary to expectations. If the mortgage rate is a proxy for buyer homeownership, then it should be positively related to TOM.

There are two reasons for the result: first, the typical mortgage term in Singapore is fairly long (up to 30 years). Furthermore, Singapore only has ARM (Adjustable Rate Mortgage) that can be floating based on the change of market conditions. Based on the fact that the adjustable mortgage rate will float a lot in such a long period, buyers will not be concerned about the mortgage rate at buying time. Even if the mortgage rate at the buying time is low, it is likely to rise later, thus the buyer will bear more cost. Second, the mortgage rate is derived from the bank's prime lending rate which is the reference interest rate index in Singapore. As the prime lending rate changes, the monthly mortgage payment varies too. As such, the mortgage rate is expected to be affected by changes in the prime lending rate in the same trend. But statistics show that the mortgage rate has the same trend with the prime lending rate from 1983 to 1999 , but a different trend from 2000 to $2002^{9}$. The period is just the study time in our paper. So, it is likely to bias our results. If the sample covers a longer period, the bias may be corrected. ${ }^{9}$ Figure 1 shows that mortgage rate has the same trend with prime lending rate from 1983 to 1999 . The
only difference between 2 indices happened from 2000 to 2002 . 
UNEMPLOY

The unemployment rate which indicates the local economy's situation has statistically significantly positive explanatory power to TOM: a worse market condition also reduces the liquidity of real estate, i.e. increases TOM.

\section{FLOOR}

A higher floor is predicted to have a major contributing factor to shorten TOM. The negative and significant coefficient on FLOOR supports the prediction. However, Ong and Koh (2000) found that flats on higher floors were not sold in a shorter time. They also indicated that the reason was that sellers demanded higher prices for flats on higher floors.

\section{Figure 1: Prime lending rate and mortgage rate}

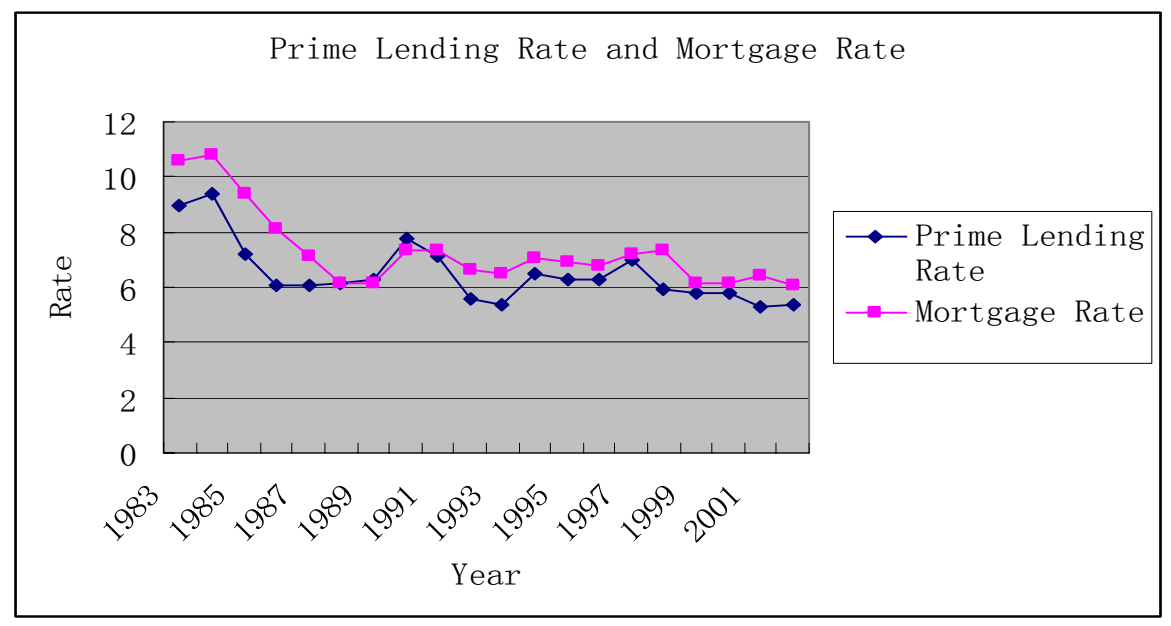

\section{$P M \& A M$}

Table 4 shows that the coefficients on AM and PM are in line with earlier prediction that the western or eastern facing linked to sunlight exposure would lengthen TOM.

\section{SIZE}

SIZE is significantly responsible for explaining TOM. The negative relationship indicates that buyers prefer the larger properties when they have decided to invest in the property market.

\section{BEDROOM \& TOILETS}

It is shown that the two variables relating to property characteristics are not significant enough to explain TOM. The probable reason is that the number of 
bedrooms and toilets are more based on a family's actual situation; for example, the number of family's members. The results are the same as in Anglin et al. (2003).

\section{POOL\& PES}

Property with a pool view or more PES is not a significant factor for TOM. It shows that they are not major contributing factors affecting TOM.

\section{$R O A D$}

Table 4 presents that the hypothesized negative relationship between ROAD and TOM is observed: the closer a property is to the main road, the shorter TOM will be.

\section{Y2001}

The positive coefficients in all price quartiles show less liquidity in the year 2001 .

\section{PRO}

PRO, which has a positive relationship with TOM, shows that the length of time to sell a unit will increase as the number of units in that project/phase increases.

\section{DUR}

DUR shows the different result from our prediction: TOM does not increase with the DUR. Table 2 shows most of the units have long DUR (The mean and median ${ }^{10}$ are both beyond 3 years). It is possible that potential buyers would rather think about other factors than DUR because all units almost have long DUR anyway.

\section{MTU}

A higher MTU will lead to longer TOM. The reason might be the higher listing price made by the developers when there is a great demand on the market. As a result, the influence of higher listing price will lengthen TOM.

\section{CTU}

The significant positive coefficient on CTU shows that competitor take-up rate affects TOM through its influence on listing price. Table 3 presents that higher CTU leads to higher listing price. Where the higher listing price surpasses the market threshold, the TOM will be longer.

\section{LIST}

The negative coefficient on LIST shows that people prefer properties developed by major leading developers, even though these properties have high listing prices.

\section{COMPSE}

COMPSE presents a positive but insignificant relationship with TOM. The reason is likely to be the same as CTU: higher listing price because of great demand in the area will lengthen TOM.

\footnotetext{
${ }^{10}$ The median of DUR is 1186.
} 
Table 5: The effect of explanatory variables in the price model and TOM model

\begin{tabular}{|c|c|c|c|c|}
\hline \multirow[b]{2}{*}{ Coefficient } & \multicolumn{2}{|c|}{ Listing Price Model } & \multicolumn{2}{|c|}{ TOM Model } \\
\hline & Expected & Actual & Expected & Actual \\
\hline DOP1 & 1 & 1 & + & $2.864 * *$ \\
\hline FLOOR & + & $0.007 * * *$ & - & $-0.028 * *$ \\
\hline FLOOR2 & l & / & + & $0.002 * *$ \\
\hline $\mathbf{P M}$ & - & $-0.034 * * *$ & + & $0.168 * * *$ \\
\hline $\mathbf{A M}$ & - & -0.007 & + & $0.178 * * *$ \\
\hline SIZE & + & $0.960 * * *$ & Not sure & $-0.832 * *$ \\
\hline SIZE2 & - & $-0.165 * * *$ & Not sure & $0.233 * *$ \\
\hline BEDROOMS & + & $0.040 * * *$ & Not sure & 0.035 \\
\hline TOILETS & + & $0.036 * * *$ & Not sure & $-0.084 * *$ \\
\hline POOL & + & $0.023 * * *$ & - & 0.032 \\
\hline ROAD & + & $0.270 * * *$ & - & $-1.352 * * *$ \\
\hline PES & + & $-0.016^{* *}$ & - & -0.064 \\
\hline R1 & Not sure & $0.047 * * *$ & Not sure & $1.009 * * *$ \\
\hline $\mathbf{R 2}$ & Not sure & $0.079 * * *$ & Not sure & $0.170 *$ \\
\hline $\mathbf{R 3}$ & Not sure & $0.091 * * *$ & Not sure & $2.005 * * *$ \\
\hline R4 & Not sure & $-0.199 * * *$ & Not sure & $1.950 * * *$ \\
\hline T99 & - & $-0.559 * * *$ & + & -0.051 \\
\hline Y2001 & l & & Not sure & $1.445 * * *$ \\
\hline PPI & + & $0.020 * * *$ & / & l \\
\hline MORTGAGE & I & l & + & $-11.494 * * *$ \\
\hline UNEMPLOY & / & / & + & $0.566 * * *$ \\
\hline COMPSE & Not sure & $0.238 * * *$ & Not sure & -0.038 \\
\hline CTU & Not sure & $0.978 * * *$ & Not sure & $8.758 * * *$ \\
\hline LIST & + & $0.113 * * *$ & Not sure & $-1.680 * * *$ \\
\hline DUR & - & $0.00002 *$ & + & $-0.002 * * *$ \\
\hline MTU & + & $0.096 * * *$ & Not sure & $1.500 * * *$ \\
\hline PRO & l & / & + & $0.026^{* * *}$ \\
\hline PRO2 & l & / & Not sure & $0.00005^{* * *}$ \\
\hline CAPITAL & + & $0.037^{*}$ & Not sure & $1.371 * * *$ \\
\hline CDL & + & $0.100 * * *$ & Not sure & $2.474 * * *$ \\
\hline KEPPEL & + & $0.171 * * *$ & Not sure & $1.287 * * *$ \\
\hline MCL & + & $0.096 * * *$ & Not sure & $-0.445 * * *$ \\
\hline
\end{tabular}

Because the results of Listing Price Model and Selling Price Model are almost same, we only take results of Listing Price model in this table. *indicates significance at the $10 \%$ level; ** indicates significance at the $5 \%$ percent level; ***indicates significance at the $1 \%$ percent level

Table 5 is the summary of the effect of explanatory variables in the price model and TOM model. Through the analysis on the TOM model, two findings should be noted: first, some of the property characteristics like POOL, BEDROOMS, 
TOILETS and PES are not significant in explaining TOM. But the variables relating to competitor behaviour significantly affect TOM. Second, it is found that the physical and locational characteristics of the property directly affect TOM; however, the factors relating to competitor behaviour affect TOM through their influence on listing price. For example, potential buyers prefer the units with high floor, southern or northern facing and convenient traffic, then TOM of this kind of units are shorter than other units. But the variables relating to competitor behaviour, for example, CTU, MTU and COMPSE, affect TOM through their influence on property price. It also shows that buyers care more about the property price especially when there are some competitors in the same area and period. So the developer cannot be optimal to list the higher price even if market demand is good.

\section{CONCLUSION}

This study has provided an empirical framework that focuses on the relationship between TOM and DOP using the data of new-sale properties in Singapore's highrise condominium market, where developer motivations differ substantially from individual seller motivations. The results show that the overpricing strategy does not pay off, but leads to longer TOM. The similar results of the two definitions of DOP reflect the appropriateness of the price strategy adopted by developers in our sample. In addition, some other factors affecting TOM, such as the property characteristics, the macroeconomic factors and the competitor strategy, are analysed as well.

The empirical results also indicate that some property characteristics, such as pool view, number of bedrooms or toilets and private enclosed space, are not significant in explaining TOM. But properties on higher floors, with southern or northern facing, and with more convenient traffic will have shorter TOM. The competitor behaviour significantly affects the TOM through their influence on listing price.

Our analysis points to a question that should be resolved: there are some factors not only affecting TOM but also property price, especially some property physical characteristics and factors relating to competitor behaviour. For example, a property facing to the north or the south will attract more buyers and shortens TOM, but the high listing price because of such good facing also leads to long TOM. How to set a suitable listing price which not only is within the buyer's search scope but also fits the property characteristics and market situations, is an area for further rigorous research.

\section{REFERENCES}

Anglin, P.M. (1997). Determinants of buyer search in a housing market. Real Estate Economics, 25, pp. 567-589. 
Anglin, P.M., Rutherford, R. and Springer, T.M. (2003). The trade-off between the selling price of residential properties and time-on-the-market: the impact of price setting. Journal of Real Estate Finance and Economics, 26:1, pp. 95-111.

Arnold, M.A. (1999). Search, bargaining and optimal asking price. Real Estate Economics, 27:3, pp. 453-481.

Bagehot, W. (1971). The only game in town. Financial Analysts Journal, 27, pp. $12-14 \& 22$.

Belkin, J., Hempel, D.J. and Mcleavey, D.W. (1976). An empirical study of time on market using multidimensional segmentation of housing markets. AREUEA Journal, 4:2, pp. 57-75.

Brealey, R.A. and Myers, S.C. (1988). Principles of Corporate Finance, McGrawHill.

Chau K.W., Ng F.F. and Hung E.C.T. (2001). Developer's good will as significant influence on apartment unit prices. The Appraisal Journal, 69, pp. 26-30.

Glower, M., Haurin, D.R. and Hendershott, P.H. (1998). Selling time and selling price: the influence of seller motivation. Real Estate Economics, 26, pp. 719-740.

Haurin, D. (1988). The duration of marketing time of residential housing. AREUEA Journal, 16, pp. 396-410.

Jud, G.D., Winkler, D. T. and Kissing, G. E. (1995). Price spreads and residential housing market liquidity. Journal of Real Estate Finance and Economics, 11, pp. 251-260.

Jud, G.D., Seaks, T.G. and Winkler, D. T. (1996). Time in the market: the impact of residential brokerage. Journal of Real Estate Research, 12, pp. 447- 458.

Kalra, R. and Chan, K. C. (1994). Censored sample bias, macroeconomic factors, and time on market of residential housing. Journal of Real Estate Research, 9, pp. $253-262$.

Kang, H.B. and Gardner, M.J. (1989). Selling price and marketing time in the residential real estate market. Journal of Real Estate Research, 4, pp. 21-35.

Kluger, B.D. and Miller, N.G. (1990). Measuring residential real estate liquidity. AREUEA Journal, 18, pp. 145-159. 
Knight, J.R. (2002). Listing price, time on market and ultimate selling price: causes and efforts of listing price changes. Real Estate Economics, 30, pp. 213-237.

Miller, N.G. (1978). Time in the market and selling price. AREUEA Journal, 6:2, pp. 164-174.

Ong, S.E. and Koh, Y.C. (2000). Time-on-market and price trade-offs in high-rise housing sub-markets. Urban Studies, 37:11, pp. 2057-2071.

Sirmans, C.F., Turnbull, G.K. and Benjamin, J.D. (1991). The markets for housing and real estate broker services. Journal of Housing Economics, 1, pp. 207- 217.

Springer, T.M. (1996). Single-family housing transactions: seller motivations, price, and marketing time. Journal of Real Estate Finance and Economics, 13, pp. 237254.

Turnbull, G.K. and Sirmans, C.F. (1993). Information, search and house prices. Regional Science and Urban Economics, 23, pp. 545-557.

Yang, S. and Yavas, A. (1995b). Bigger is not better: brokerage and time in the market. Journal of Real Estate Research, 10, pp. 23-33.

Yavas, A. and Yang, S. (1995a). The strategic role of listing price in marketing real estate: theory and evidence. AREUEA Journal, 23, pp. 347-368.

Zuehlke, T.W. (1987). Duration dependence in the housing market. Review of Economics and Statistics, 69, pp. 701-704. 